\title{
Anti-Inflammatory Effect of Emblica officinalis in Rodent Models of Acute and Chronic Inflammation: Involvement of Possible Mechanisms
}

\author{
Mahaveer Golechha, ${ }^{1,2}$ Vikas Sarangal, ${ }^{1}$ Shreesh Ojha, ${ }^{3}$ \\ Jagriti Bhatia, ${ }^{1}$ and Dharmveer S. Arya ${ }^{1}$ \\ ${ }^{1}$ Department of Pharmacology, All India Institute of Medical Sciences, New Delhi 110029, India \\ ${ }^{2}$ Public Health Foundation of India, New Delhi 110070, India \\ ${ }^{3}$ Department of Pharmacology and Therapeutics, Faculty of Medicine \& Health Sciences, UAE University, P.O. Box 17666, Al Ain, UAE
}

Correspondence should be addressed to Dharmveer S. Arya; dsarya16@hotmail.com

Received 30 May 2014; Revised 31 July 2014; Accepted 12 August 2014; Published 21 August 2014

Academic Editor: Andrew S. Day

Copyright (C) 2014 Mahaveer Golechha et al. This is an open access article distributed under the Creative Commons Attribution License, which permits unrestricted use, distribution, and reproduction in any medium, provided the original work is properly cited.

Emblica officinalis, commonly known as amla in Ayurveda, is unarguably the most important medicinal plant for prevention and treatment of various ailments. The present study investigated the anti-inflammatory activity of hydroalcoholic extract of Emblica officinalis (HAEEO). Acute inflammation in rats was induced by the subplantar injection of carrageenan, histamine, serotonin, and prostaglandin $\mathrm{E}_{2}$ and chronic inflammation was induced by the cotton pellet granuloma. Intraperitoneal (i.p.) administration of HAEEO at all the tested doses $(300,500$, and $700 \mathrm{mg} / \mathrm{kg})$ significantly $(P<0.001)$ inhibited rat paw edema against all phlogistic agents and also reduced granuloma formation. However, at the dose of $700 \mathrm{mg} / \mathrm{kg}$, HAEEO exhibited maximum anti-inflammatory activity in all experimental models, and the effects were comparable to that of the standard anti-inflammatory drugs. Additionally, in paw tissue the antioxidant activity of HAEEO was also measured and it was found that HAEEO significantly $(P<0.001)$ increased glutathione, superoxide dismutase, and catalase activity and subsequently reduced lipid peroxidation evidenced by reduced malondialdehyde. Taken all together, the results indicated that HAEEO possessed potent anti-inflammatory activity and it may hold therapeutic promise in the management of acute and chronic inflammatory conditions.

\section{Introduction}

Inflammation plays a major role in rheumatoid arthritis and osteoarthritis [1]. In clinics, the nonsteroidal antiinflammatory drugs (NSAIDs) are commonly prescribed for pain relief in arthritic conditions. However, their continual use is associated with serious adverse effects like gastric mucosal damage, occult blood loss and elevation of serum hepatic transaminases, salt and water retention, and also exacerbation of asthma [2]. In order to circumvent these adverse effects associated with conventional NSAIDs, novel selective COX-2 inhibitors are in progress. However, the development of serious adverse reactions, like cardiovascular events with rofecoxib and Stevens-Johnson syndrome with valdecoxib, has compelled their withdrawal from use [3].
Additionally, the clinical uses of the remaining drugs in this class have been prescribed with caution and have consequently decreased [4].

In milieu of these observations patients as well as health care providers prefer to use alternative therapeutic agents as they are considered to be safe and effective in alleviating inflammation associated with arthritis. Several Indian medicinal plants were reported as an important source of new chemical moieties with potential therapeutic effects [5]. The studies on plants with substantiated folkloric use as antiinflammatory agents are viewed as a productive and logical research strategy in the search for new anti-inflammatory drugs

Emblica officinalis Gaertn. (Euphorbiaceae) commonly known as amla grow in the tropical areas of South-East 
Asia. The fruit of the plant is one of the most important medicinal ingredients used in Ayurveda, Siddha, Unani, Arabic, Tibetan, and various other folk systems for the management of myriad chronic ailments [6]. Experimental studies have shown potent antioxidant, analgesic, antipyretic, adaptogenic, immunomodulatory, and antiulcerogenic activities of the fruit of Emblica officinalis [6-8].

The fruits are reported to contain thermostable vitamin C, minerals, amino acids, tannins, flavonoids, and other important phytochemicals which are believed to possess diverse pharmacological and biological effects [9]. Earlier studies have shown that the leaf extract possesses anti-inflammatory activities in the carrageenan and dextran-induced rat hind paw edema [10]. However, studies on the fruit extract which is the most used part of amla have never been performed. Therefore, the present study was carried out to evaluate the anti-inflammatory activity of the hydroalcoholic extract of the fruit of Emblica officinalis (HAEEO) in both acute and chronic models of inflammation in rats. Further, in order to understand the possible underlying mechanism, the effect of extract on the oxidative stress produced by carrageenan was also studied in the rat paw.

\section{Methodology}

2.1. Plant Extract. The standardized lyophilized hydroalcoholic extract of the fruit of Emblica officinalis (HAEEO) was procured from Sanat Products Limited, India (A WHOGMP and ISO 9001 Accredited Herbal Extract Manufacturer Company). The voucher specimen of lyophilized extract of the fruits of Emblica officinalis (number EO 0114) was deposited at Department of Pharmacology, All India Institute of Medical Sciences, New Delhi, India. The phytochemical analysis was done by using HPLC (Waters, Milford Massachusetts, USA). The extract obtained was of the highest purity with $28.26 \% \mathrm{w} / \mathrm{w}$ of hydrolysable tannins emblicanin $A$ and emblicanin B on dried weight basis.

2.2. Drugs and Chemicals. Carrageenan, histamine, 5hydroxytryptamine (serotonin), chlorpheniramine, cyproheptadine, prostaglandin $\mathrm{E}_{2}\left(\mathrm{PGE}_{2}\right)$, and bovine serum albumin were purchased from Sigma Chemicals, St. Louis, MO, USA. Indomethacin was procured from Cipla, India. All other chemicals and reagents were of analytical grade.

2.3. Experimental Animals. All experimental procedures described were reviewed and approved by the Institutional Animal Ethics Committee and care of animals was taken as per guidelines of CPCSEA, Ministry of Environment and Forest, Government of India. Wistar albino rats of either sex weighing 180-200 g were used for the study. The animals were procured from the central animal facility in All India Institute of Medical Sciences, New Delhi. The rats were group-housed in polypropylene cages with no more than four animals per cage. They were maintained under standard laboratory conditions with natural dark-light cycle and were allowed free access to standard pellet diet (Golden Feeds, India) and tap water ad libitum. All the experiments were carried out using five groups, each containing 6 animals (Groups I-V) except carrageenan-induced paw edema where Groups I-VI were used.

\subsection{Determination of Anti-Inflammatory Activity of HAEEO on Acute Inflammation}

2.4.1. Carrageenan-Induced Hind Paw Edema in Rats. Acute inflammation was produced by injecting $0.1 \mathrm{~mL}$ of carrageenan ( $1 \%$ in saline) locally into the plantar aponeurosis of the right hind paw of the rats $[11,12]$. Group I served as normal control, where no inflammation was induced. This group was used for evaluation of biochemical parameters. Groups II and III received vehicle (saline $1 \mathrm{~mL} / \mathrm{kg}$, i.p.) and standard drug indomethacin $(10 \mathrm{mg} / \mathrm{kg}$, p.o.), respectively, and served as vehicle and positive controls. HAEEO (300, 500, and $700 \mathrm{mg} / \mathrm{kg}$, i.p.) was administered to Groups IV, V, and VI, respectively. The HAEEO or vehicle was administered $30 \mathrm{~min}$ prior to injection of carrageenan and indomethacin was orally administered $1 \mathrm{~h}$ prior to the injection of carrageenan. The pedal volume up to the ankle joint was measured using a digital plethysmometer (Ugo Basile, 7140 Comerio, Varese, Italy) at $0 \mathrm{~h}$ (just before carrageenan injection) and then at $3 \mathrm{~h}$. The different timing was chosen because of the different route of drug administration. The $\%$ inhibition of edema volume between treated and control groups was calculated as follows: $\%$ Inhibition $=V_{c}-V_{t} \times 100 / V_{c}$, where $V_{c}$ and $V_{t}$ represent the mean increase in paw volume in control and treated groups, respectively.

2.4.2. Autacoids-Induced Hind Paw Edema in Rats. This experiment was conducted according to the method described by Singh and Pandey [13]. The autacoids serotonin $(1 \mathrm{mg} / \mathrm{mL})$, histamine $(1 \mathrm{mg} / \mathrm{mL})$, and prostaglandin $\mathrm{E}_{2}(1 \mu \mathrm{g} /$ $\mathrm{mL}$ ) were employed as phlogistic agents. The effect of HAEEO (300, 500, and $700 \mathrm{mg} / \mathrm{kg}$, i.p.) and vehicle was tested individually against each autacoid. The anti-inflammatory effect of HAEEO was compared with that of standard drugs against each autacoid: phenylbutazone (PBZ, $100 \mathrm{mg} / \mathrm{kg}$, p.o.) against prostaglandin $\mathrm{E}_{2}$, chlorpheniramine (CPM, $3 \mathrm{mg} / \mathrm{kg}$, p.o.) against histamine, and cyproheptadine $(\mathrm{CPH}, 3 \mathrm{mg} / \mathrm{kg}$, p.o.) against serotonin. Right hind paw edema was induced by the subplantar injection of $0.1 \mathrm{~mL}$ of different phlogistic agents in the respective groups. HAEEO was administered i.p. $30 \mathrm{~min}$ prior to inflammatory insult and standard reference drugs were administered p.o. $1 \mathrm{~h}$ prior to the inflammatory insult. The pedal volume was measured just before $(0 \mathrm{~h})$ and then at $3 \mathrm{~h}$ after the phlogistic challenge.

\subsection{Determination of Anti-Inflammatory Activity of HAEEO on Chronic Inflammation}

2.5.1. Cotton Pellet-Induced Granuloma in Rats. The cotton pellet-induced granuloma in rats was studied according to the method of D'Arcy et al. [14]. The animals were divided into five groups with six animals in each group. The rats were anaesthetized and sterile cotton pellets weighing $10 \pm 1 \mathrm{mg}$ were implanted subcutaneously into both sides of the groin 


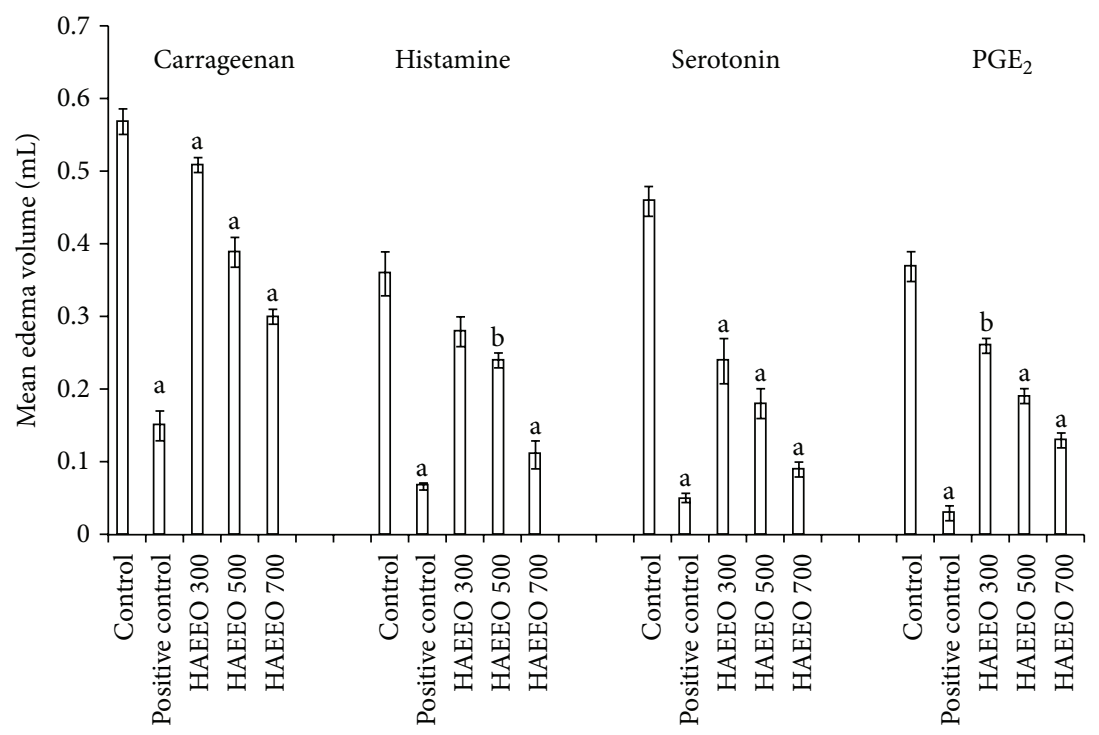

FIGURE 1: Effect of HAEEO on carrageenan- and autacoids-induced hind paw edema in rats. Each value represents the mean \pm S.E.M. $(n=$ 6). ${ }^{\mathrm{a}} \mathrm{P}<0.001$ and ${ }^{\mathrm{b}} \mathrm{P}<0.01$ compared to control. Positive control carrageenan (indomethacin $10 \mathrm{mg} / \mathrm{kg}$ ), histamine (chlorpheniramine $3 \mathrm{mg} / \mathrm{kg}$ ), serotonin (cyproheptadine $3 \mathrm{mg} / \mathrm{kg}$ ), and $\mathrm{PGE}_{2}$ (phenylbutazone $100 \mathrm{mg} / \mathrm{kg}$ ). HAEEO: hydroalcoholic extract of Emblica officinalis.

region of each rat. Group I served as control and received the vehicle. HAEEO in the doses of 300, 500, and $700 \mathrm{mg} / \mathrm{kg}$, i.p. was administered to animals in groups II, III, and IV for seven consecutive days from the day of cotton pellet implantation. Group V received indomethacin (10 mg/kg, p.o.) for the same period. On day 8, the animals were anaesthetized and the pellets together with the attached granuloma tissue were carefully removed and freed from extraneous tissues. The wet pellets were weighed and then dried in an oven at $60^{\circ} \mathrm{C}$ for $24 \mathrm{~h}$ to a constant weight; after that the dried pellets were weighed again. Increment in the dry weight of the pellets was taken as a measure of granuloma formation.

2.6. Determination of Levels of Oxidative Stress Parameters. The biochemical markers of oxidative stress were determined in the carrageenan-induced rat paw edema model. Animals were euthanized $3 \mathrm{~h}$ after measurement of paw volume and the inflamed paw tissue was removed and processed for the estimation of oxidative stress. Paw tissue samples were thawed and homogenized with 10 times (w/v) ice-cold $0.1 \mathrm{M}$ phosphate buffer ( $\mathrm{pH}$ 7.4). Aliquots of homogenates from paw tissue were used to determine the malondialdehyde (MDA) [15] and glutathione [16]. The remaining homogenates were centrifuged at $7000 \mathrm{rpm}$ for $30 \mathrm{~min}$ at $4^{\circ} \mathrm{C}$ temperature and the supernatant was used for estimation of superoxide dismutase (SOD) [17], catalase [18], and protein [19].

2.7. Statistical Analysis. Data were expressed as mean \pm S.E.M. Statistical differences between the treatment and the respective control groups were evaluated by one-way ANOVA followed by Tukey-Kramer post hoc test. $P<0.05$ was considered to be statistically significant.

\section{Results}

3.1. Carrageenan-Induced Hind Paw Edema in Rats. The mean increase in paw edema volume was $1.0 \pm 0.02 \mathrm{~mL}$ in the vehicle-treated control rats. All the three doses of HAEEO $(300,500$, and $700 \mathrm{mg} / \mathrm{kg}$, i.p.) produced a dosedependent significant $(P<0.001)$ reduction in the mean paw edema volume (Figure 1). The percentage inhibition in paw edema volume as compared to the vehicle treated group was $48.9,60.2$, and $70.0 \%$ for HAEEO, respectively. The standard drug, indomethacin (10 mg/kg, p.o.), exhibited maximum anti-inflammatory activity with $84.27 \%$ inhibition.

3.2. Effect of HAEEO on Changes in Tissue Levels of $M D A, G S H, S O D$, and Catalase. Carrageenan injection into the subplantar tissue of the rat paw decreased the tissue GSH, catalase, and SOD levels (Table 1). Both HAEEO and indomethacin produced a significant increase in the endogenous antioxidants in a dose dependent manner to maintain oxidative homeostasis. Carrageenan injection produced significant lipid peroxidation, as evidenced by a marked increase in the levels of MDA. Both HAEEO and indomethacin produced a significant decrease in the levels of MDA. HAEEO at $700 \mathrm{mg} / \mathrm{kg}$ dose most effectively stabilized the oxidative stress parameters.

3.3. Autacoid-Induced Hind Paw Edema in Rats. A dosedependent effect of HAEEO on hind paw edema was observed. The $700 \mathrm{mg} / \mathrm{kg}$ dose of HAEEO was the most effective (Figure 1). It significantly $(P<0.001)$ inhibited hind paw edema induced by histamine (68.47\%), serotonin (79.26\%), and $\mathrm{PGE}_{2}$ (64.00\%). Phenylbutazone $(100 \mathrm{mg} / \mathrm{kg}$, p.o.), chlorpheniramine (3 mg/kg, p.o.), and cyproheptadine 
TABLE 1: Effect of HAEEO on oxidative stress parameters in carrageenan-induced paw edema in rats.

\begin{tabular}{lcccc}
\hline Treatment & GSH $\left(\mu \mathrm{g} \mathrm{g}^{-1}\right.$ tissue $)$ & MDA $\left(\mathrm{nmol} \mathrm{g}^{-1}\right.$ tissue $)$ & SOD $\left(\mathrm{U} \mathrm{mg}^{-1}\right.$ protein$)$ & Catalase $\left(\mathrm{U} \mathrm{mg}^{-1} \mathrm{protein}\right.$ \\
\hline Normal control & $32.91 \pm 2.13$ & $27.14 \pm 2.96$ & $40.54 \pm 2.23$ & $57.19 \pm 2.48$ \\
Carrageenan control (vehicle treated) & $13.33 \pm 1.39^{\mathrm{a}}$ & $88.45 \pm 4.79^{\mathrm{a}}$ & $15.19 \pm 1.21^{\mathrm{a}}$ & $14.48 \pm 0.75^{\mathrm{a}}$ \\
Indomethacin $\left(10 \mathrm{mg} \mathrm{kg}^{-1}\right)$ & $26.66 \pm 1.66^{\mathrm{b}}$ & $28.54 \pm 6.85^{\mathrm{b}}$ & $31.96 \pm 1.08^{\mathrm{b}}$ & $49.30 \pm 1.86^{\mathrm{b}}$ \\
HAEEO $\left(300 \mathrm{~m} \mathrm{~kg}^{-1}\right)$ & $19.16 \pm 1.53$ & $63.18 \pm 4.51^{\mathrm{d}}$ & $21.18 \pm 1.80$ & $27.44 \pm 1.66^{\mathrm{b}}$ \\
HAEEO $\left(500 \mathrm{~m} \mathrm{~kg}^{-1}\right)$ & $22.29 \pm 2.80^{\mathrm{d}}$ & $49.14 \pm 5.83^{\mathrm{b}}$ & $24.87 \pm 0.98^{\mathrm{d}}$ & $36.1 \pm 0.83^{\mathrm{b}}$ \\
HAEEO $\left(700 \mathrm{~m} \mathrm{~kg}^{-1}\right)$ & $26.25 \pm 2.18^{\mathrm{c}}$ & $35.10 \pm 2.78^{\mathrm{b}}$ & $29 \pm 1.66^{\mathrm{b}}$ & $41.82 \pm 1.41^{\mathrm{b}}$ \\
\hline
\end{tabular}

Values given are mean \pm S.E.M. $(n=6) .{ }^{\mathrm{a}} P<0.001$ compared to normal control and ${ }^{\mathrm{b}} P<0.001,{ }^{\mathrm{c}} P<0.01$, and ${ }^{\mathrm{d}} P<0.05$ compared to carrageenan control. HAEEO: hydroalcoholic extract of Emblica officinalis; GSH: glutathione; MDA: malondialdehyde; SOD: superoxide dismutase.

TABLE 2: Effect of HAEEO on cotton pellet-induced granuloma in rats.

\begin{tabular}{lcc}
\hline Group & Weight of cotton pellet granuloma (mg) & Protection percentage \\
\hline Control (vehicle treated) & $53.81 \pm 1.94$ & - \\
Positive control (indomethacin $\left.10 \mathrm{mg} \mathrm{kg}^{-1}\right)$ & $18.96 \pm 2.18^{\mathrm{a}}$ & 64.76 \\
HAEEO $\left(300 \mathrm{mg} \mathrm{kg}^{-1}\right)$ & $35.23 \pm 1.48^{\mathrm{a}}$ & 34.52 \\
HAEEO $\left(500 \mathrm{mg} \mathrm{kg}^{-1}\right)$ & $30.30 \pm 0.94^{\mathrm{a}}$ & 43.69 \\
HAEEO $\left(700 \mathrm{mg} \mathrm{kg}^{-1}\right)$ & $25.63 \pm 1.29^{\mathrm{a}}$ & 52.36 \\
\hline
\end{tabular}

Each value represents the mean \pm S.E.M. $(n=6)$. ${ }^{\mathrm{a}} P<0.001$ compared to control. HAEEO: hydroalcoholic extract of Emblica officinalis.

(3 mg/kg, p.o.) also significantly $(P<0.001)$ inhibited hind paw edema induced by $\mathrm{PGE}_{2}(92.00 \%)$, histamine $(82.06 \%)$, and serotonin $(89.56 \%)$, respectively (Figure 1$)$.

3.4. Cotton Pellet-Induced Granuloma. The study of HAEEO on proliferative phase of inflammation indicated that HAEEO $(300,500$, and $700 \mathrm{mg} / \mathrm{kg}$, i.p. $)$ significantly $(P<0.001)$ and dose-dependently reduced the granuloma formation (Table 2). Indomethacin (10 mg/kg, p.o.) exhibited significant $(P<0.001)$ and maximum inhibition on granuloma formation.

\section{Discussion and Conclusion}

In the present study, it was observed that Emblica officinalis possessed potent anti-inflammatory activity both in acute and chronic rat models of inflammation. Inflammation is part of the host defense system and is triggered by a variety of noxious stimuli. It involves a complex interplay between cellcell, cell-mediator, and tissue interactions [20]. Carrageenaninduced rat paw edema model is a well-established model for evaluating anti-inflammatory drugs [21]. The edema and inflammation induced by carrageenan are a biphasic event. In the initial $1 \mathrm{~h}$ after carrageenan administration, the edema and inflammation are mediated by histamine and serotonin. Later, the increased vascular permeability is maintained by the release of kinins up to about $2.30 \mathrm{~h}$. Thereafter from $2.30 \mathrm{~h}$ to $6 \mathrm{~h}$, inflammation is mediated by prostaglandins and is also associated with migration of leucocytes into the inflamed site [22].

Carrageenan-induced paw edema model in rats is known to be sensitive to cyclooxygenase (COX) inhibitors and has been used to investigate the effect of nonsteroidal antiinflammatory agents [23]. The result of the present study indicated that HAEEO afforded protection against the carrageenan-induced acute inflammation in dose dependent manner. HAEEO at a dose of $700 \mathrm{mg} / \mathrm{kg}$ exhibited significant anti-inflammatory activity with $70.0 \%$ inhibition of paw edema and was comparable to the indomethacin group. In autacoid-induced models of inflammations (against serotonin, histamine, and $\mathrm{PGE}_{2}$ ), HAEEO produced significant inhibitory activity. The present study exhibited HAEEO's anti-inflammatory action by means of inhibiting the synthesis, release, or action of inflammatory mediators like histamine, serotonin, and prostaglandins that are involved in inflammation. In earlier study on the anti-inflammatory activity of leaf extracts of Emblica officinalis in carrageenanand dextran-induced rat paw edema models, it was reported that the extracts did not inhibit the synthesis of the lipid mediators $\mathrm{LTB}_{4}, \mathrm{TXB}_{2}$, or PAF [24]. Therefore, it is quite possible that a composite effect may have been responsible for the observed protection against autacoids-induced inflammation.

The role of excess generation of nitric oxide (NO) in inflammatory response is well studied. Inflammation or tissue damage leads to induction of iNOS (inducible nitric oxide synthase); consequently large amounts of NO are generated at the site of inflammation [25]. NO reacts with superoxide anion to form peroxynitrite, an oxidizing molecule capable of eliciting lipid peroxidation. In lipid peroxidation there is oxidative deterioration of polyunsaturated lipids to form radical intermediates that causes cellular damage [26]. MDA is a major end product of this reaction and an index of lipid peroxidation that is measurable by estimating as thiobarbituric acid reactive substance (TBARS) [27]. The present study showed that both HAEEO (500 and $700 \mathrm{mg} / \mathrm{kg}$ ) and indomethacin $(10 \mathrm{mg} / \mathrm{kg})$ decreased the levels of MDA.

The infiltrating inflammatory cells also generate reactive oxygen species (ROS) and free radicals. The most common 
ROS include the superoxide anion, hydroxyl radical, singlet oxygen, and hydrogen peroxide. The enzyme superoxide dismutase catalyzes the dismutation of superoxide into oxygen and hydrogen peroxide. The activity of SOD reduces during severe inflammation as well as in the presence of oxidative stress [28]. The large quantities of hydrogen peroxide generated are then taken care of by catalase and glutathione peroxidase $(\mathrm{GPx})$ to water. Excessive production of lipid hydroperoxide may also lead to reduced activity of GPx in inflammatory conditions [29]. Besides the enzymatic antioxidants, the level of glutathione, a nonenzymatic reducing agent that traps free radicals and prevents oxidative damage, is also diminished in inflammatory conditions [30]. Both HAEEO $(700 \mathrm{mg} / \mathrm{kg})$ and indomethacin $(10 \mathrm{mg} / \mathrm{kg})$ maintained the oxidative homeostasis, and the levels of reduced glutathione and activities of catalase and SOD were comparable to the control animals.

Experimental studies have shown the potent antioxidant property of the fruit of Emblica officinalis [31]. Various phytochemical constituents of the plant such as emblicanins $\mathrm{A}$ and $\mathrm{B}$, gallic acid, and ellagic acids have been identified as powerful free radical scavengers [9]. Moreover, other phytochemicals with $\mathrm{NO}$ scavenging properties like Geraniin, Corilagin, and Furosin have been reported in the Emblica officinalis fruit extract [32]. Recently, it has also been reported that the superoxide scavenging properties of Emblica officinalis extract approximate those of L-ascorbic acid, a well-established antioxidant [33].

In order to assess the efficacy of HAEEO against chronic inflammation, the cotton pellet granuloma model in rats was employed. HAEEO at all doses tested significantly $(P<0.001)$ reduced the granuloma formation. The maximum effect was observed at the dose of $700 \mathrm{mg} / \mathrm{kg}$ with $52.36 \%$ inhibition in granuloma formation as compared to the control group. Although the exact mechanism of antiinflammatory activity of HAEEO on proliferative phase of inflammation in this model is not known, it may be hypothesized that both the antioxidant and the immunomodulatory properties of the plant may have been responsible for the protective action of the extract. Emblica officinalis extract has been reported to inhibit NF- $\kappa$ B activation, a key transcription factor involved in chronic inflammatory response and ageing [34]. The inhibition of NF- $\kappa$ B leads to reduction in the iNOS and COX-2 enzyme levels.

The main adverse effect of nonsteroidal anti-inflammatory drugs is their ability to produce gastric lesions [35]. Furthermore, Sairam et al. [36] demonstrated the ulcer protective potential of Emblica officinalis in different acute gastric ulcer models in rats induced by aspirin, ethanol, cold restraint stress, and pyloric ligation and healing effect in chronic gastric ulcers induced by acetic acid in rats. The antiulcerogenic activity of Emblica officinalis is definitely complementary to the good anti-inflammatory and antioxidant activity observed in the present study. Further, it has been shown that Emblica officinalis was well tolerated in mice even at the dose of $2.5 \mathrm{~g} / \mathrm{kg}$ [37].

In conclusion, the present study clearly demonstrated that HAEEO possessed potent anti-inflammatory activity and also scientifically validated the traditional use of this plant for treating inflammatory disorders in the folk medicine. The advantages of HAEEO, namely, better and safer antiinflammatory profile with potent antiulcerogenic activity, deserve further studies to establish the therapeutic value and elucidate the mechanism of action in the treatment of different inflammatory diseases.

\section{Conflict of Interests}

The authors declare that there is no conflict of interests regarding the publication of this paper.

\section{References}

[1] K. D. Moudgil and B. M. Berman, "Traditional Chinese medicine: potential for clinical treatment of rheumatoid arthritis," Expert Review of Clinical Immunology, vol.10, no. 7, pp. 819822, 2014.

[2] Z. Varga, M. Kriška, V. Kristová, and M. Petrová, “Analysis of non-steroidal anti-inflammatory drug use in hospitalized patients and perception of their risk," Interdisciplinary Toxicology, vol. 6, no. 3, pp. 141-144, 2013.

[3] E. Z. Dajani and K. Islam, "Cardiovascular and gastrointestinal toxicity of selective cyclo-oxygenase- 2 inhibitors in man," Journal of Physiology and Pharmacology, vol. 59, no. 2, pp. 117-133, 2008.

[4] T. Santiago and J. A. P. da Silva, "Safety of low- to mediumdose glucocorticoid treatment in rheumatoid arthritis: myths and reality over the years," Annals of the New York Academy of Sciences, pp. 41-49, 2014.

[5] Galib, B. Patgiri, and P. Prajapati, "Pharmacological attributes of Indian medicinal plants with special reference to their antiinflammatory activity," Ancient Science of Life, vol. 28, no. 3, pp. 36-39, 2009.

[6] K. R. Thilakchand, R. T. Mathai, P. Simon, R. T. Ravi, M. P. Baliga-Rao, and M. S. Baliga, "Hepatoprotective properties of the Indian gooseberry (Emblica officinalis Gaertn): a review," Food \& Function, vol. 4, no. 10, pp. 1431-1441, 2013.

[7] M. S. Baliga and J. J. Dsouza, "Amla (Emblica officinalis Gaertn), a wonder berry in the treatment and prevention of cancer," European Journal of Cancer Prevention, vol. 20, no. 3, pp. 225239, 2011.

[8] M. S. Baliga, S. Meera, B. Mathai, M. P. Rai, V. Pawar, and P. L. Palatty, "Scientific validation of the ethnomedicinal properties of the Ayurvedic drug Triphala: a review," Chinese Journal of Integrative Medicine, vol. 18, no. 12, pp. 946-954, 2012.

[9] M. J. Feeney, "Fruits and the prevention of lifestyle-related diseases," Clinical and Experimental Pharmacology and Physiology, vol. 31, supplement 2, pp. S11-S13, 2004.

[10] M. Z. Asmawi, H. Kankaanranta, E. Moilanen, and H. Vapaatalo, "Anti-inflammatory activities of Emblica officinalis Gaertn leaf extracts," Journal of Pharmacy and Pharmacology, vol. 45, no. 6, pp. 581-584, 1993.

[11] G. Amresh, G. D. Reddy, C. V. Rao, and P. N. Singh, "Evaluation of anti-inflammatory activity of Cissampelos pareira root in rats," Journal of Ethnopharmacology, vol. 110, no. 3, pp. 526-531, 2007.

[12] C. A. Winter, E. A. Risley, and G. W. Nuss, "Carrageenininduced edema in hind paw of the rat as an assay for antiiflammatory drugs," Proceedings of the Society for Experimental Biology and Medicine, vol. 111, pp. 544-547, 1962. 
[13] R. K. Singh and B. L. Pandey, "Anti-inflammatory activity of seed extracts of Pongamia pinnata in rat," Indian Journal of Physiology and Pharmacology, vol. 40, no. 4, pp. 355-358, 1996.

[14] P. F. D’Arcy, E. M. Howard, P. W. Muggleton, and S. B. Townsend, "The anti-inflammatory action of griseofulvin in experimental animals," Journal of Pharmacology and Pharmacotherapeutics, vol. 12, no. 1, pp. 659-565, 1960.

[15] H. Ohkawa, N. Ohishi, and K. Yagi, "Assay for lipid peroxides in animal tissues by thiobarbituric acid reaction," Analytical Biochemistry, vol. 95, no. 2, pp. 351-358, 1979.

[16] G. L. Ellman, “Tissue sulfhydryl groups," Archives of Biochemistry and Biophysics, vol. 82, no. 1, pp. 70-77, 1959.

[17] S. Marklund and G. Marklund, "Involvement of the superoxide anion radical in the autoxidation of pyrogallol and a convenient assay for superoxide dismutase," European Journal of Biochemistry, vol. 47, no. 3, pp. 469-474, 1974.

[18] H. Aebi, "[13] Catalase in vitro," Methods in Enzymology, vol. 105, pp. 121-126, 1984.

[19] M. M. Bradford, "A rapid and sensitive method for the quantitation of microgram quantities of protein utilizing the principle of protein dye binding," Analytical Biochemistry, vol. 72, no. 1-2, pp. 248-254, 1976.

[20] A. Geremia, P. Biancheri, P. Allan, G. R. Corazza, and A. di Sabatino, "Innate and adaptive immunity in inflammatory bowel disease," Autoimmunity Reviews, vol. 13, no. 1, pp. 3-10, 2014.

[21] C. J. Morris, "Carrageenan-induced paw edema in the rat and mouse," Methods in Molecular Biology, vol. 225, pp. 115-121, 2003.

[22] R. F. Queiroz, A. K. Jordão, A. C. Cunha et al., "Nitroxides attenuate carrageenan-induced inflammation in rat paws by reducing neutrophil infiltration and the resulting myeloperoxidasemediated damage," Free Radical Biology and Medicine, vol. 53, no. 10, pp. 1942-1953, 2012.

[23] S. Bansal, M. Bala, S. K. Suthar et al., "Design and synthesis of novel 2-phenyl-5-(1,3-diphenyl-1H-pyrazol-4-yl)-1,3,4oxadiazoles as selective COX-2 inhibitors with potent antiinflammatory activity," European Journal of Medicinal Chemistry, vol. 80C, pp. 167-174, 2014.

[24] A. Ihantola-Vormisto, J. Summanen, H. Kankaanranta, H. Vuorela, Z. M. Asmawi, and E. Moilanen, "Anti-inflammatory activity of extracts from leaves of Phyllanthus emblica," Planta Medica, vol. 63, no. 6, pp. 518-524, 1997.

[25] C. Ziskoven, M. Jäger, J. Kircher et al., "Physiology and pathophysiology of nitrosative and oxidative stress in osteoarthritic joint destruction," Canadian Journal of Physiology and Pharmacology, vol. 89, no. 7, pp. 455-466, 2011.

[26] S. Saeidnia and M. Abdollahi, "Toxicological and pharmacological concerns on oxidative stress and related diseases," Toxicology and Applied Pharmacology, vol. 273, no. 3, pp. 442455, 2013.

[27] E. Ho, K. K. Galougahi, C.-C. Liu, R. Bhindi, and G. A. Figtree, "Biological markers of oxidative stress: applications to cardiovascular research and practice," Redox Biology, vol. 1, no. 1, pp. 483-491, 2013.

[28] G.-J. Huang, S. S. Huang, and J.-S. Deng, "Anti-inflammatory activities of inotilone from Phellinus linteus through the inhibition of MMP-9, NF- $\kappa \mathrm{B}$, and MAPK activation in vitro and in vivo," PLoS ONE, vol. 7, no. 5, Article ID e35922, 2012.

[29] S. Mohsin, G. M. Kurup, and R. Mahadevan, "Effect of ascophyllan from brown algae Padina tetrastromatica on inflammation and oxidative stress in carrageenan-induced rats," Inflammation, vol. 36, no. 6, pp. 1268-1278, 2013.

[30] A. Bishayee and M. Chatterjee, "Time course effects of vanadium supplement on cytosolic reduced glutathione level and glutathione S-transferase activity," Biological Trace Element Research, vol. 48, no. 3, pp. 275-285, 1995.

[31] B. Hazra, R. Sarkar, S. Biswas, and N. Mandal, "Comparative study of the antioxidant and reactive oxygen species scavenging properties in the extracts of the fruits of Terminalia chebula, Terminalia belerica and Emblica officinalis," BMC Complementary and Alternative Medicine, vol. 10, article 20, 15 pages, 2010.

[32] S. K. Jain and D. S. Khurdiya, "Vitamin C enrichment of fruit juice based ready-to-serve beverages through blending of Indian gooseberry (Emblica officinalis Gaertn.) juice," Plant Foods for Human Nutrition, vol. 59, no. 2, pp. 63-66, 2004.

[33] A. Muthuraman, S. Sood, and S. K. Singla, "The antiinflammatory potential of phenolic compounds from Emblica officinalis L. in rat," Inflammopharmacology, vol. 19, no. 6, pp. 327-334, 2011.

[34] T. Yokozawa, H. Y. Kim, H. J. Kim, T. Okubo, D.-C. Chu, and L. R. Juneja, "Amla (Emblica officinalis Gaertn.)prevents dyslipidaemia and oxidative stress in the ageing process," British Journal of Nutrition, vol. 97, no. 6, pp. 1187-1195, 2007.

[35] M. Pairet, L. Churchill, G. Trummlitz, and G. Engelhardt, "Differential inhibition of cyclooxygenase-1 (COX-1) and 2 (COX-2) by NSAIDs: consequences on anti-inflammatory activity versus gastric and renal safety," Inflammopharmacology, vol. 4, no. 1, pp. 61-70, 1996.

[36] K. Sairam, C. V. Rao, M. D. Babu, K. V. Kumar, V. K. Agrawal, and R. K. Goel, "Antiulcerogenic effect of methanolic extract of Emblica officinalis: an experimental study," Journal of Ethnopharmacology, vol. 82, no. 1, pp. 1-9, 2002.

[37] K. B. Hari Kumar, M. C. Sabu, P. S. Lima, and R. Kuttan, "Modulation of haematopoetic system and antioxidant enzymes by Emblica officinalis Gaertn and its protective role against $\gamma$-radiation induced damages in mice," Journal of Radiation Research, vol. 45, no. 4, pp. 549-555, 2004. 


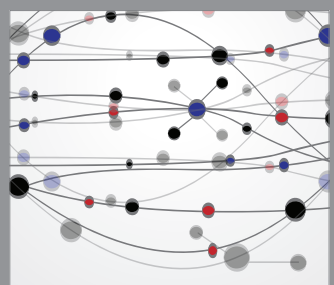

The Scientific World Journal
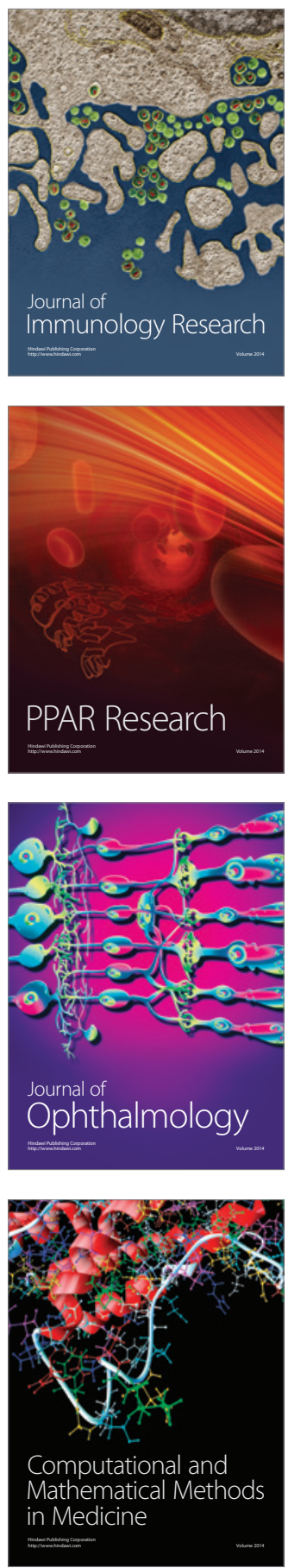

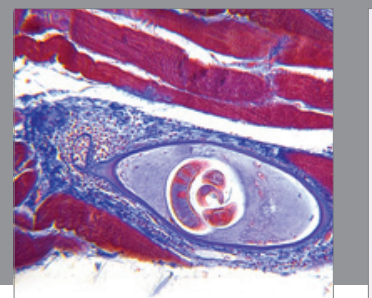

Gastroenterology

Research and Practice


\section{Hindawi}

Submit your manuscripts at

http://www.hindawi.com
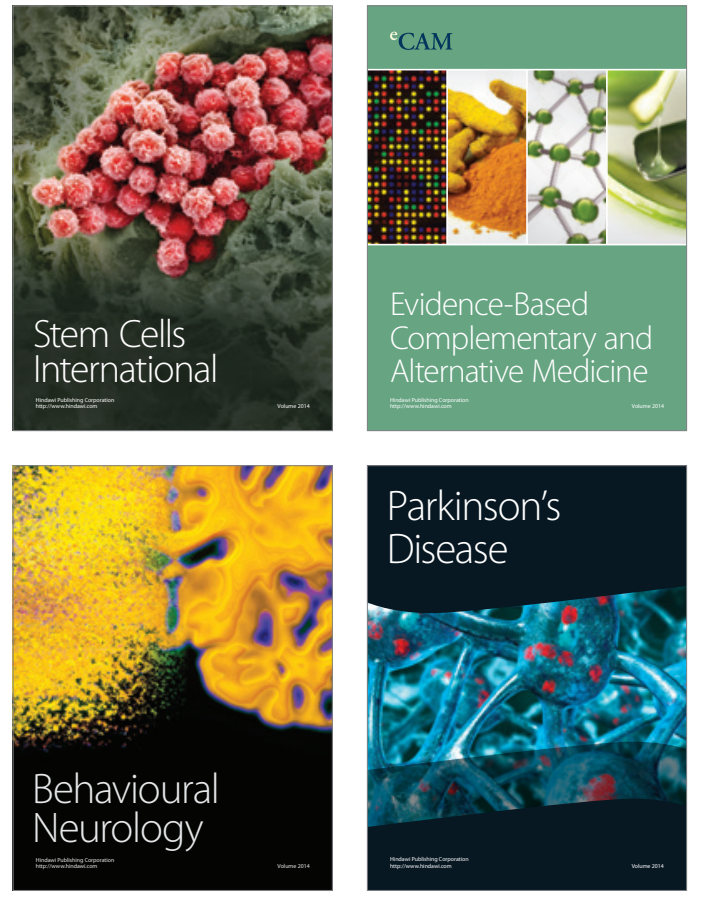
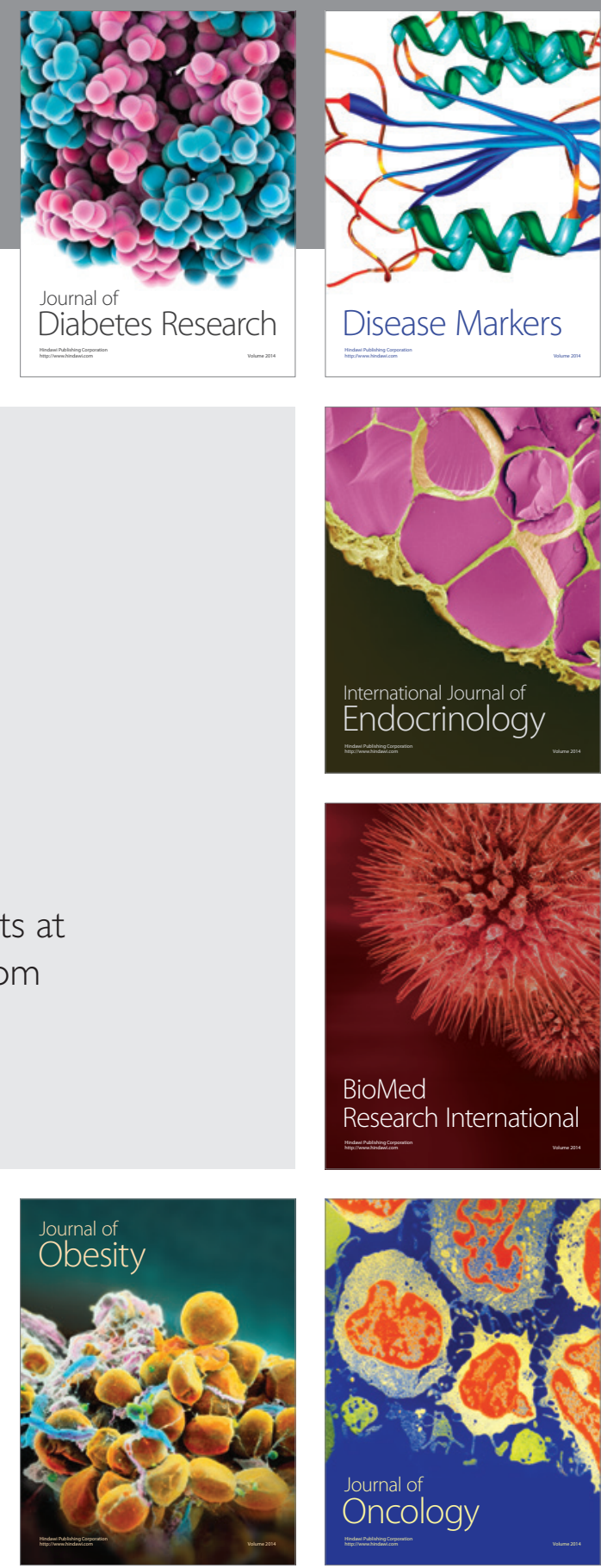

Disease Markers
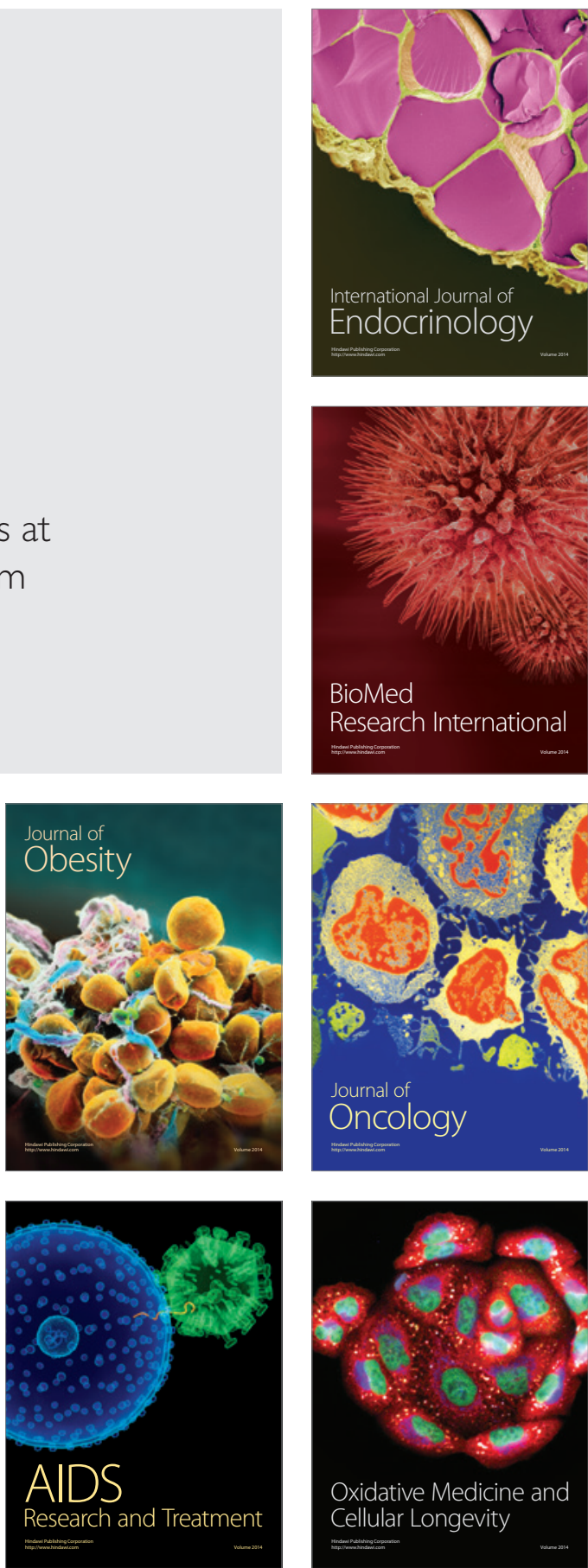